University of Wollongong

Research Online

Faculty of Social Sciences - Papers (Archive) Faculty of Arts, Social Sciences \& Humanities

2014

Phonological reduction in maternal speech in northern Australian English: Change over time

Heather Buchan

University of Wollongong, hb307@uowmail.edu.au

Caroline Jones

University of Wollongong, carjones@uow.edu.au

Follow this and additional works at: https://ro.uow.edu.au/sspapers

Part of the Education Commons, and the Social and Behavioral Sciences Commons

Research Online is the open access institutional repository for the University of Wollongong. For further information contact the UOW Library: research-pubs@uow.edu.au 


\title{
Phonological reduction in maternal speech in northern Australian English: Change over time
}

\author{
Abstract \\ Segmental variation in maternal speech to children changes over time. This study investigated variation in \\ non-citation speech processes in a longitudinal, 26-hour corpus of maternal northern Australian English. \\ Recordings were naturalistic parent-child interactions when children $(N=4)$ were $1 ; 6,2 ; 0$ and 2;6. The \\ mothers' speech was phonetically transcribed and analysed. Based on previous sociophonetic research \\ showing proportional changes in speech variants in maternal speech as children get older, it was \\ predicted that deletion of word-initial /h/ and word-final / $/$, processes common in non-citation speech, \\ would increase over time. Instead results showed a non-linear change in deletion within a stable set of \\ lexical items. Deletion proportionately increased between $1 ; 6$ and 2;0 and decreased between 2;0 and 2;6. \\ Further analysis indicated increased deletion was not accounted for by changes in speech rate, which \\ only marginally increased over time. Findings suggest mothers fine-tune differentially over time as \\ children's receptive and productive language knowledge develops.
}

\section{Keywords}

change, english, australian, northern, speech, maternal, reduction, time, phonological, over

\section{Disciplines}

Education | Social and Behavioral Sciences

\section{Publication Details}

Buchan, H. \& Jones, C. (2014). Phonological reduction in maternal speech in northern Australian English: Change over time. Journal of Child Language, 41 (4), 725-755. 


\section{Journal of Child Language}

http://journals.cambridge.org/JCL

Additional services for Journal of Child

Language:

Email alerts: $\underline{\text { Click here }}$

Subscriptions: Click here

Commercial reprints: $\underline{\text { Click here }}$

Terms of use : $\underline{\text { Click here }}$

\section{Phonological reduction in maternal speech in northern Australian English: change over time}

HEATHER BUCHAN and CAROLINE JONES

Journal of Child Language / Volume 41 / Issue 04 / July 2014, pp 725 - 755

DOI: 10.1017/S0305000913000123, Published online: 03 July 2013

Link to this article: http://journals.cambridge.org/abstract S0305000913000123

How to cite this article:

HEATHER BUCHAN and CAROLINE JONES (2014). Phonological reduction in maternal speech in northern Australian English: change over time. Journal of Child Language, 41, pp 725-755 doi:10.1017/S0305000913000123

Request Permissions : $\underline{\text { Click here }}$ 


\title{
Phonological reduction in maternal speech in northern Australian English: change over time*
}

\author{
HEATHER BUCHAN \\ Interdisciplinary Educational Research Institute (IERI) and \\ Faculty of Education, University of Wollongong; NHMRC Centre for \\ Research Excellence in Mental Health and Substance Use, National Drug and \\ Alcohol Research Centre, University of New South Wales \\ AND \\ CAROLINE JONES \\ Interdisciplinary Educational Research Institute (IERI) and \\ Faculty of Education, University of Wollongong; The MARCS Institute, \\ University of Western Sydney
}

(Received 7 November 201 I - Revised 1 F Fuly 2012-Accepted 31 Fanuary 2013-

First published online 3 Fuly 2013)

\section{ABSTRACT}

Segmental variation in maternal speech to children changes over time. This study investigated variation in non-citation speech processes in a longitudinal, 26-hour corpus of maternal northern Australian English. Recordings were naturalistic parent-child interactions when children $(N=4)$ were I ; 6, 2;0, and $2 ; 6$. The mothers' speech was phonetically transcribed and analyzed. Based on previous sociophonetic research showing proportional changes in speech variants in maternal speech as children get older, it was predicted that deletion of word-initial $/ \mathrm{h} /$ and word-final $/ \mathrm{v} /$, processes common in non-citation speech, would increase over time. Instead results showed a non-linear change in deletion within a stable set of lexical items. Deletion proportionately increased between I; 6 and 2;0 and decreased between 2;0 and 2;6. Further analysis indicated increased deletion was not accounted for by

[*] The authors thank the audience at the I2th International Congress for the Study of Child Language (IASCL 20I I) for their feedback on an early version of this paper. We also thank two anonymous reviewers for their helpful suggestions. The authors thank the speakers and their families for participating in the study, and the childcare services in Katherine, NT, in particular Good Beginnings Australia and Little Mangoes childcare centre. The research was supported by Discovery Grant DPo985395 'Phonological development in child speakers of mixed language' (2009-2012, C.I. Caroline Jones) from the Australian Research Council. Address for correspondence: Heather Buchan: e-mail h.buchan@unsw.edu.au 
changes in speech rate, which only marginally increased over time. Findings suggest mothers fine-tune differentially over time as children's receptive and productive language knowledge develops.

Children's phonological knowledge is shaped by their exposure to spoken language, and their phonological development includes learning the systematic phonetic variation that is a part of everyday speech. Variation in the speech input that children are often exposed to, known as infant- or child-directed speech, differs from that in inter-adult speech (adult speech directed to other adults) in lexical and syntactic structures as well as in phonetic features such as tempo, pitch, and frequency (Fernald, Taeschner, Dunn, Papousek, de Boysson-Bardies \& Fukui, I989). Phonetic variation in infant-directed speech changes systematically over time, as caregivers' speech to their children becomes more like inter-adult speech as children get older. For example it has been found cross-linguistically that mothers tend to use hyperarticulated vowels when talking to their infants aged 0;2-0; 5 compared with their speech to other adults (Kuhl et al., I997). A longitudinal study on child-directed speech found that, compared with inter-adult speech, Mandarin-speaking mothers used hyperarticulated vowels when children were prelinguistic, aged $0 ; 7-\mathbf{I} ; 0$, and at age $5 ; 0-5 ; 9$ (Liu, Tsao \& Kuhl, 2009). Further, vowels were more hyperarticulated to children at $0 ; 7-1 ; 0$ than at $5 ; 0-5 ; 9$, in that they were longer, had a higher pitch, and the vowel space was larger so vowels were more distinct from one another, suggesting mothers modify their speech differently as their children get older (Liu et al., 2009).

Few studies have examined segmental variation and changes in maternal speech after infancy and even fewer have used longitudinal data. Much of the literature on speech input to children has focused on the first year of life, as this is a crucial period for children's language development (Jusczyk, Cutler \& Redanz, I 993; Jusczyk, Friederici, Wessels, Svenkerud \& Jusczyk, I993; Jusczyk, Luce \& Charles-Luce, I994; Kuhl, Williams, Lacerda, Stevens \& Lindblom, I992). Research has found differences in segmental distributions between mothers' speech to children aged $\mathbf{I} ; 0$ and to adults (Lee \& Davis, 2010; Lee, Davis \& MacNeilage, 2008), indicating segment patterns in maternal speech change sometime after the first year of life to eventually develop into adult-directed speech.

Further research is needed in order to understand how child-directed speech develops into adult-directed and at what ages the changes take place. Early research on segmental differences between child- and adult-directed speech suggests that the period between child ages $\mathrm{I} ; \mathrm{O}$ and $2 ; 6$ is a time of extensive variability in the input, and longitudinal analysis could be useful in elucidating how variability in mothers' speech changes around these ages. Findings of these early studies were mixed in regard to the type of variation 
and the nature of the phonological differences in speech directed to children and to adults. However, the age of the children varied between studies and relatively large age ranges were used within studies. Bernstein-Ratner (1984a, I984b), for example, found more vowel lengthening, which is a feature of hyperarticulation (Liu et al., 2009), in child-directed speech to children aged $0 ; 9-2 ; 3$ than in adult-directed speech, and more consonant reduction in adult-directed than child-directed speech. Vowel hyperarticulation is a clarification process while consonant reduction refers to reduced or deleted consonants, so these studies suggested mothers modify their speech to pronounce segments more carefully and clearly when speaking to children.

Other early research, however, found that reduction was more frequent in speech to children than speech to adults (Shockey \& Bond, r980), and that isolated segments were less intelligible in child-directed than inter-adult speech (Bard \& Anderson, I983). A discussion of these early studies by Cruttenden (I 994) argued that children's own language development may be a mediating factor, as the clarification processes were found in speech to children who were prelinguistic or starting to produce single words while more reduction and less intelligibility than inter-adult speech was found in speech to older children, generally over 2 ; 0 . A recent study on speaking rate in child-directed speech also found that age 2;0 is associated with a shift in mothers' speech. Ko (2012) analyzed mothers' speech rate in longitudinal data from twenty-five speakers in the CHILDES database (MacWhinney, 2000). Ko (2012) performed a break-point analysis and found that in general a non-linear function fit the data significantly better than a linear model, and that the break-point tended to occur around age 2 ; 0 to $2 ; 5$. Results showed large individual differences in the direction of the pattern. However, the non-linear shift in mothers' speech around child age 2; 0 was consistently significant. It is possible that the mixed findings in the early child-directed speech studies are due to linear or non-linear changes in mothers' speech over time, as mothers change their speech depending on their children's age and/or communicative development.

The phonology of adult speech to children also varies as a function of speech style. In a corpus of caregiver-child speech recorded in Scotland, Smith, Durham and Fortune (2007) found that caregivers' use of variable phonetic forms changed depending on their speech style. The timing of children's acquisition of stylistic variation in relation to their acquisition of linguistic (phonological and grammatical) constraints appears to vary depending on the type of variable being acquired (Labov, r 989; Roberts, I 997; Youssef, I 99I). Kerswill and Williams (2000) suggest that children gradually acquire stylistic variation over time as they gain sociolinguistic competence, and Labov (200I) suggests that stylistic variation in caregiver speech plays a key role in children's acquisition of variable forms. 
Cruttenden (I994) suggests phonetic modifications made in speech to children may serve different functions at different child ages and stages of language development. For example, exaggerated prosodic features in mothers' speech peak in the first six months (Stern, Spieker \& Barnett, I983), and this may function to help infants attend to the speech signal and develop sensitivity to affect expressed in speech (Cruttenden, I994). Similarly the apparent peak in hyperarticulation when children start to produce intelligible words may function to clarify segments to ease perception (Cruttenden, I994). This explanation relates to the concept of fine-tuning: that mothers modify their speech according to their perceptions of their child's receptive and productive language.

In addition to fine-tuning to children's linguistic development, there is evidence that mothers may also fine-tune to children's understanding of social categories indexed in speech, such as age, sex, region, and socioeconomic status. Variation in phonetic segments due to socioindexical variables is termed 'sociophonetic variation' (Foulkes \& Docherty, 2006), and in speech to children this type of variation introduces children to phonetic forms associated with speakers' identities and social groups in the speech community. The few studies that have examined sociophonetic variation in caregiver speech suggest that it does change as children age. Smith, Durham, and Fortune (2009) analyzed mothers' speech to children aged 2; I I to 3; I I in a Scottish dialect of English. They examined t/d deletion in word-final consonant clusters, a reduction process common in non-citation inter-adult speech across English dialects that has been studied widely as a sociolinguistic marker (for a review see Tagliamonte \& Temple, 2005). Findings showed that rates of $\mathrm{t} / \mathrm{d}$ deletion tended to be higher in speech to the older than the younger children, suggesting sociophonetic modifications in maternal speech may also vary with child age.

Sociophonetic variation associated with regional vernacular has also been shown to change over time in mothers' speech to children after infancy. Foulkes, Docherty, and Watt (2005) analyzed a cross-sectional sample of mothers' speech to children aged between 2 ; 0 and 4 ; 0 in a nonstandard variety of English from Tyneside in northeastern England. The phonetic segments analyzed were variants of $/ t /$ in word-medial intersonorant and word-final prevocalic positions, as the realization of $/ t /$ in these contexts is a sociolinguistic marker in Tyneside English (Foulkes et $a l ., 2005)$. Pronunciation of the segment as [t] was considered standard, while $[\mathrm{I}]$ and glottals in these contexts were considered non-standard variants that are characteristic of the region and may not be held in high regard outside the speech community. Foulkes et al. (2005) found that overall, child-directed speech contained a higher proportion of the standard [t] variant compared with inter-adult speech. Standard [t] was relatively less frequent in speech to older than younger children while the non-standard 
variants were relatively more frequent in speech to the older children. It is suggested that phonetic variation in mothers' speech changes over time to gradually familiarize children with the alternate phonetic forms common in inter-adult non-citation speech, and that socioindexical variation functions to facilitate children's learning of the social meanings associated with phonetic variants as well as phonological category boundaries (Foulkes \& Docherty, 2006; Foulkes et al., 2005). These studies on sociophonetic variation in speech to children indicate that mothers may fine-tune their speech to their perceptions of children's socioindexical as well as linguistic knowledge.

An explanation of how children may learn systematic phonetic variation from speech input can be found in exemplar-based models of phonological development, such as Pierrehumbert's (2003) model. According to this approach all tokens contain both linguistic (e.g., acoustic) and socioindexical information, which is encoded concurrently for each exemplar and associated with frequency distributions (Foulkes \& Docherty, 2006; Pierrehumbert, 2003). Munson, Edwards, and Beckman (20I I) suggest that learning to map sociophonetic variation involves developing another level of representation for socioindexical information. This level may provide another source of top-down information for children to draw on when interpreting phonetic variability in the speech signal (Munson et al., 20II). The strength of representations may depend on the frequency and recency of exemplars (Pierrehumbert, 2003), that is the stored memories of tokens, and so variable input over time during early childhood could shape representations at different levels of mapping. Usage-based models of phonological acquisition are supported by studies on children's acquisition of liaison consonants in French. Liaison is a phonological process that occurs variably in French connected speech, depending on linguistic factors and socioeconomic status (SES) (Chevrot, Dugua \& Fayol, 2009; Chevrot, Nardy \& Barbu, 20 I I). SES differences in children's productions of liaison consonants reflect those in adult speech and increase as children age from 2; 0 to 6; (Chevrot et al., 20I I). Chevrot et al. (2009) suggest that children acquire variation by first encoding multiple exemplars of the variable lexical forms in the input and then abstracting information from the exemplar store to form schemas.

In addition to social meanings of segmental variation, children are exposed to variation associated with speech acts and social interactions. Phonetic variation can be associated with style shifting, which is learned throughout childhood and related to caregiver usage (Kerswill \& Williams, 2000). Mothers' use of either standard or local vernacular variants has been found to be constrained by situation in a Scottish dialect of English, with more vernacular variants used in the informal contexts of play and routine speech than the formal contexts of discipline and teaching (Smith et al., 
2007). Introducing children to situational variation may be another function of modifications made in speech to children.

In summary, children are exposed to systematic phonetic variation from early on in life. Phonetic modifications made in maternal speech change over time as child-directed speech develops into inter-adult speech, but there is relatively little literature on how and when this happens as children get older. There is some evidence that infant- and child-directed speech has different functions depending on the age and linguistic development of the child, and this may drive changes in variation in the input over time as mothers fine-tune their speech to their perceptions of children's receptive and productive language. The few studies that have examined variation in maternal speech to children after infancy suggest mothers may also shape modifications in their speech to their perceptions of children's knowledge of socioindexical factors, and there are also likely to be situational constraints on mothers' use of non-standard phonetic forms. In the current study we investigated how variation in non-citation speech changes in mothers' speech to children from ages $\mathrm{I} ; 6$ to $2 ; 6$ in a regional variety of Australian English. To get a clearer understanding of when mothers might start using more processes in non-citation speech, this study started with children of a younger age than those in the Foulkes et al. (2005) study, in which children were aged 2;0 to 4;0, and the Smith et al. (2009) study, in which children were aged between 2; I I and 3; II. In the current study we started with children aged $\mathrm{I} ; 6$.

\section{Phonetic variation in Australian English}

The phonological system of standard Australian English is well established, although regional dialects have generally not been studied in detail. Standard Australian English differs from other standard English varieties in the realization of many of the vowels, prosodic patterns, lexical items, and paralinguistic characteristics (Harrington, Cox \& Evans, I 997). In a recent description of the main phonological features of Australian English, standard Australian English is described as 'the dominant dialect used by the vast majority of speakers' (Cox \& Palethorpe, 2007: 34I) in Australia today. Being a multicultural country there are many other dialects spoken, which have previously been broadly grouped into 'Aboriginal English' and 'Ethnocultural Australian English' categories (Cox \& Palethorpe, 2007). There may also be varieties differing on other dimensions such as geographic region, but this has not been studied in depth owing to a historical perception that there is relatively low regional variation in Australian English.

However, recent research has found some regionally distributed vowel characteristics (Cox \& Palethorpe, 2004) as well as variation in vowel 
'broadness' by region and other socioeconomic factors (Cox \& Palethorpe, 2010). Relatively less research into Australian English has focused on consonants (Ingram, I 989; Tollfree, 200 I). Sociolinguistic studies of consonant variation include Horvath ( 1985 ) and Ingram ( 1989 ); both found significant effects of sociolinguistic variables on consonant processes. Horvath's ( 1985 ) study included 'h dropping' (/h/ deletion) and Ingram's (I989) study investigated connected speech processes. In Australian English, /h/ deletion is considered a sociolinguistic feature which correlates with socioeconomic status and gender; connected speech processes (assimilation, elision) are also socially correlated and were one of five variables differentiating the 'classical' accent classes in Australian English: broad, general, and cultivated (Mitchell \& Delbridge, r965).

Horvath (1985) analyzed consonant variants in Australian English speech from I 7 speakers in Sydney, New South Wales. Data were from the Sydney Urban Dialect Survey, a sociolinguistic survey which involved interviews conducted with a stratified sample of Australian English speakers from Sydney, including speakers of English as a second language. Horvath ( 1985 ) conducted principal components analyses to identify four main 'sociolects' based on sex, age, socioeconomic status, and ethnicity, and analyzed the frequency of six consonant processes to compare the incidence of these processes in the 'sociolect' subgroups. One consonant process she examined was word-initial $/ \mathrm{h} /$ deletion (I).

(I) go get him $\rightarrow$ go get 'im

Along with other consonant processes considered typical of 'broad' Australian English speakers, word-initial /h/ deletion was generally more frequent in males, teenagers, and speakers from 'lower working class' backgrounds (Horvath, I 985). In dialects of English in England, 'h dropping' is also a known sociolinguistic marker (Tollfree, I999; Wells, I 982; Williams \& Kerswill, I 999).

Ingram (1989) examined connected speech processes according to socioeconomic status in adolescent speakers from Brisbane, Queensland. One type of connected speech process is the articulatory simplification that often occurs in fast non-citation speech, leading to phonetic assimilation and reduction (2). The frequency of connected speech processes account for much of the phonological differences between citation and non-citation speech, and vary with speech rate, register, and 'broadness' (Ingram, I 989).

(2) I don't know about him $\rightarrow$ I dunno 'bout 'im

One consonant process that Ingram (1989) analyzed was cluster reduction, and it was noted that cluster reduction largely affected word-final /nt/, /nd/, and /st/ clusters. Ingram ( 1989) found that the frequency of consonant cluster reduction was relatively high in both working-class and 
middle-class adolescents, and there was no significant difference between the two groups. There was, however, a significant difference between working-class and middle-class adolescents in the frequency of other speech processes. Deletion of $/ \mathrm{h} /$ occurred significantly more often in the speech of the working-class than the middle-class participants, and was most common in third person pronoun forms. The working-class group were also significantly more likely to delete schwas (e.g. 'bout for about) and word-initial interdental fricatives (e.g. ' $\mathrm{em}$ for them). These findings show sociolinguistic factors affect connected speech processes among Australian-English speakers. In the present study we consider word-initial /h/ deletion and the speech process word-final /v/ deletion in a little-described variety of northern Australian English. In the absence of sociolinguistic evidence for this dialect, we refer to these as non-citation speech processes henceforth.

\section{Katherine English}

Katherine is a small regional town in the Northern Territory, Australia, located about 3 I 7 kilometres south of Darwin, the Northern Territory capital. The English spoken in Katherine, which we term Katherine English, was sampled for the current study as a variety of regional Australian English. This language variety has been the subject of just one previous study (Jones, Meakins \& Buchan, 20 I I), and no sociolinguistic research, so we offer comments from speakers to characterize the sociolinguistic setting. Terms that speakers used to describe Katherine English included 'very casual', 'relaxed', 'slang', 'country-sounding', 'not as refined', ' rough', and 'ocker' (slang for a stereotypically uncultivated Australian), Speakers also say - we lack objective data - that their words tend to be simpler and not as long, and that the speech of Southerners (people from outside the Northern Territory or city people) is 'fuller' in that they use longer words, more words, and fewer shortened versions. Overall, speakers suggest that Katherine English may be considered a casual or relaxed variety of Australian English with a relatively high use of vernacular in everyday non-citation speech.

\section{The current study}

The aim of this study was to examine how phonetic variation related to non-citation speech processes in regional Australian English maternal speech changes as children age. We collected and analyzed a corpus of naturalistic speech from mothers when their children were aged I ;6, $2 ; 0$, and $2 ; 6$. This study is part of a larger project on fricative variation in maternal speech in northern Australia (Buchan, 2013), which involves a comparison of the similarities and differences in fricative variation in 
Katherine English and an Aboriginal contact language variety in the region, Gurindji Kriol. Gurindji Kriol contains extensive fricative variation in Kriol-derived words, i.e., of English historical origin (Meakins, 20 I I). Because fricative variation is the focus of the larger project, in this study we examined variants in fricatives that are related to processes in non-citation speech. Word position effects are also being investigated in the Aboriginal language variety, and so in this study we analyzed a word-initial and a word-final fricative.

The phonetic variants we chose to measure were word-initial /h/ deletion (3a, b) based on the previous findings from Horvath (1985) and Ingram ( 1989 ), and word-final /v/ deletion (4a, b), which are regarded as processes that occur in non-citation speech (or lexical alternatives, depending on the analysis adopted):

\section{Standard form}

(3a) Go get her!

(4a) Get out of there.

Containing deletion

(3b) Go get 'er!

(4b) Get outta there.

We analyzed deletion across function and content words. Previous research has found that phonological information is important for classifying word class, and that phonological reduction is more likely to occur in function than content words (Cutler, I 993; Monaghan, Chater \& Christiansen, 2005). It was therefore expected that, overall, deletion would be more frequent in function words.

In this study maternal speech is the main source of speech input for the target children and is defined as all speech spoken by the mother around the target child. This is based on Soderstrom's (2007) definition of speech input to children, and studies that have found children learn from overhearing inter-adult speech as well as speech directed specifically to them (Akhtar, 2005; Au, Knightly, Jun \& Oh, 2002; Martinez-Sussman, Akhtar, Diesendruck \& Markson, 20 I I).

Based on recent studies showing child-directed speech to older children gradually changes to be more like inter-adult speech over time (Foulkes et al., 2005; Smith et al., 2009), it was predicted that mothers would be more likely to use the reduced variants as children got older.

\section{METHOD}

\section{Participants}

Four mothers and their children participated in the recording sessions, which were conducted at three stages six months apart when the children 
BUCHAN AND JONES

TABLE I. Participant characteristics

\begin{tabular}{|c|c|c|c|c|c|c|c|}
\hline Mother & $\begin{array}{l}\text { Target } \\
\text { child }\end{array}$ & $\begin{array}{l}\text { Target } \\
\text { child's } \\
\text { sex }\end{array}$ & $\begin{array}{l}\text { Mother's } \\
\text { education }\end{array}$ & $\begin{array}{l}\text { Family } \\
\text { position }\end{array}$ & $\begin{array}{l}\text { Stage I } \\
\text { child } \\
\text { age }\end{array}$ & $\begin{array}{c}\text { Stage } 2 \\
\text { child } \\
\text { age }\end{array}$ & $\begin{array}{c}\text { Stage } 3 \\
\text { child } \\
\text { age }\end{array}$ \\
\hline Cathy* & Lucy* & female & Bachelor degree & only child & $\mathrm{I} ; 5$ & I ; I I & $2 ; 5$ \\
\hline Kim & George & male & Secondary school & $\begin{array}{l}\text { youngest } \\
\text { of three }\end{array}$ & $\mathrm{I} ; 5$ & I ; I I & $2 ; 5$ \\
\hline Kellie & Tyson & male & Secondary school & only child & $\mathrm{I} ; 7$ & $2 ; \mathrm{I}$ & $2 ; 7$ \\
\hline Erin* & Grace* & female & Bachelor degree & $\begin{array}{l}\text { oldest of } \\
\text { three }\end{array}$ & I $; 6$ & $2 ; 0$ & $2 ; 8 \dagger$ \\
\hline
\end{tabular}

NOTES: * pseudonyms used at mother's discretion; $\dagger$ the age difference between Stage 2 and 3 is greater for Grace than the other target children because these sessions were recorded later due to participant circumstances.

were aged approximately I;6, 2;0, and 2;6. Exact ages are shown in Table 1 . A fifth mother participated but her child was six months older than the others so her data are not included in this study, as she was only recorded at two of the time-points under investigation here and therefore cannot be analyzed longitudinally.

Mothers were monolingual Australian-English speakers living in Katherine, Northern Territory, Australia. Three mothers had grown up in Katherine, while the fourth had grown up in a small regional town in northwestern Queensland, Australia. The highest educational attainment was a Bachelor degree (two mothers) and secondary school (two mothers). Mothers were recruited through local childcare centres and other local businesses, and were paid for their time.

Two of the target children had siblings, and there was also some participation in the sessions from other family members and visitors. Mothers were instructed to focus on the target child, so mothers' interactions with other people were generally minimal. Table I shows the target children's sex, their ages at each stage, and the mothers' education levels, and is followed by a brief description of the dyads and other people present in the recording sessions. Only the mothers' speech was analyzed for this study. Informed consent was obtained from or on behalf of all participants.

Cathy and Lucy. Lucy was Cathy's only child. Lucy's father occasionally participated in recordings, but in the majority of the sessions Cathy and Lucy were the only participants.

Kim and George. George had two older siblings, a boy and girl aged $6 ; 3$ and $3 ; \circ$, respectively, at Stage $\mathrm{I}$. One or both of the siblings participated in most of the sessions. Kim was asked to focus on George in the sessions, so generally the siblings played together while Kim played with George. The children's father participated occasionally. 
Kellie and Tyson. Tyson was an only child. Tyson's grandmother was present in most of the sessions. Other adult family members were sometimes in the vicinity but did not participate in sessions.

Erin and Grace. Grace had two younger brothers: one aged 0;5 at Stage I, and another born between Stages 2 and 3. Sessions were held when the younger children were mostly sleeping, so the majority of interactions were between Erin and Grace. Two adult males who work for Erin and her husband were occasionally present in some of the sessions.

\section{Procedure}

Speech samples were recorded to make a corpus of naturalistic maternal speech for the analysis of sound patterns that the children are typically exposed to. Audiovisual recordings were made in a natural setting, with each mother and child recorded at their home or at a local park, with care taken to choose quiet environments with minimal background noise. All the recordings were made by the first author, who spent time before and after each recording session talking with the participants about both the research project and unrelated subjects to build rapport. Mothers were aware that the project was about their speech, and were debriefed on the details after the final recording session.

Before each recording mothers were asked to do free play with their children and reminded that they could stop the session at any time. Participants played with materials brought by the researcher and their own toys and games. The most common activities across children and stages were drawing and painting, and playing with coloured blocks, toy cars, dolls, and playdough. Other activities included swingsets and other playground equipment, and general outside activities such as feeding pets.

The mother and target child each wore a wireless, cardioid, condenser lapel microphone (Sennheiser $\mathrm{ME}_{\mathrm{I}} \mathrm{o}_{4}$ ) that recorded high-quality audio (at $48 \mathrm{kHz}, 24 \mathrm{bit}$ ) via bodypack transmitter to a receiver with XLR connection to a hard disc recorder (Edirol R-44), in separate audio tracks for mother and child. The mother's audio track was used for transcription. The acoustic quality of the recordings was high, and with the cardioid lapel microphone positioned upwards at the top centre of the mother's shirt her speech was recorded clearly on her audio track. As recordings were made in busy naturalistic environments, occasionally a background noise was too loud to clearly hear the speech. In these cases speech was marked as unclear in the transcripts and was not analyzed. A spectrogram of an utterance from a typical recording is shown in Figure $\mathrm{I}$. This example was recorded outdoors in a park by a river and has a dynamic range of $52 \mathrm{~dB}$. The researcher also filmed sessions with a video camera (Sony AVCHD HDR XR-500V) that had a camera-mounted microphone. Several recording sessions were 
TABLE 2. Total and mean lengths of recording sessions (hh:mm:ss)

\begin{tabular}{|c|c|c|c|c|}
\hline Mother & Child age $\mathbf{I} ; 6$ & Child age $2 ; 0$ & Child age $2 ; 6$ & Total \\
\hline Cathy & $02: 05: 3 \mathrm{I}$ & O2:00: I 8 & $02: 44: 58$ & $06: 50: 47$ \\
\hline Kim & $02: 11: 37$ & oI:38:00 & $02: 28: 12$ & o6: I 7:49 \\
\hline Kellie & $02: 4 I: 54$ & $03: 07: 20$ & $02: 24: 54$ & ०8: I 4:०8 \\
\hline Erin & OI:39:48 & ০০:47:53 & O2:06:I 3 & $04: 33: 54$ \\
\hline Total & $08: 38: 50$ & $07: 33: 3 \mathrm{I}$ & $09: 44: 17$ & $25: 56: 38$ \\
\hline Mean & $02: 09: 43$ & $I: 53: 23$ & $02: 26: 05$ & \\
\hline
\end{tabular}

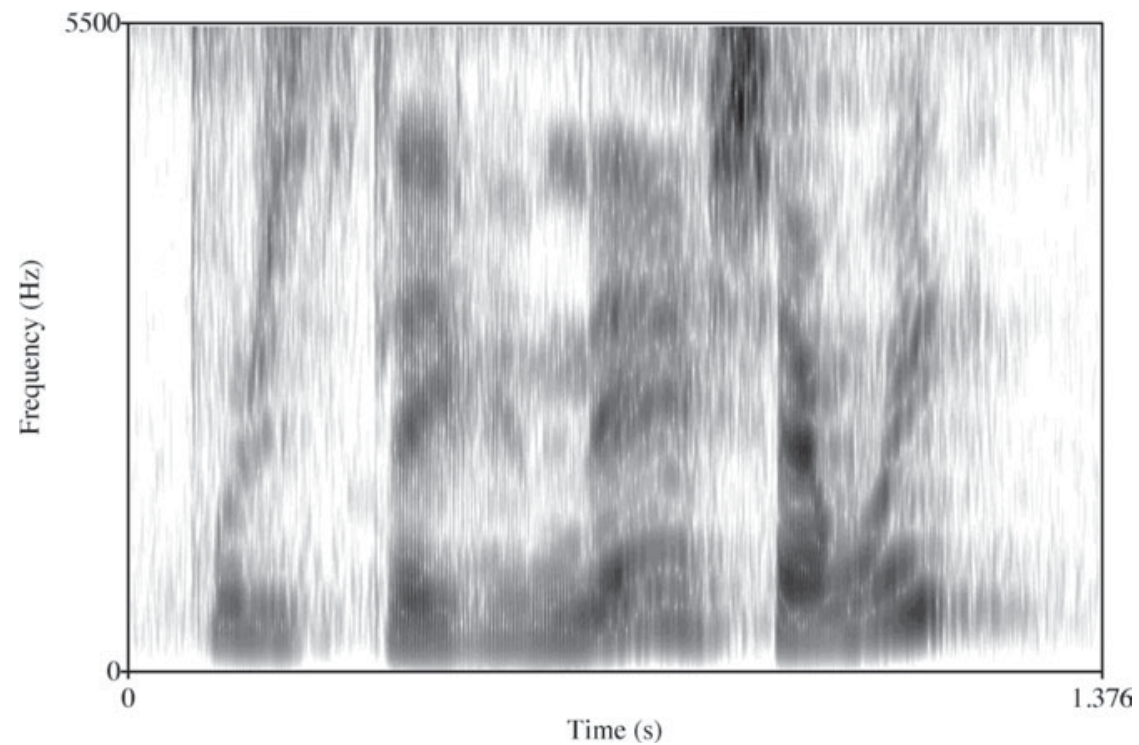

Fig. I. Spectrogram of utterance 'There we go, we'll just leave him there, shall we?'

conducted with each mother at each stage over one to three weeks, to produce in total between 8 and I I hours of recording time at each stage as detailed in Table 2. The amount of recording depended on mothers' availability and the children's compliance. Most sessions went for half an hour to an hour in length, and usually ended when the child or children got tired.

Mothers' speech was transcribed from the audio using the phonological analysis and transcription software Phon (Rose, Hedlund, Byrne, Wareham \& MacWhinney, 2007). Phonetic transcriptions were made of the mothers' actual pronunciation as well as the standard Australian-English form. Transcription was done by the first author, a native Australian-English speaker, using the transcription system recommended by Harrington et al. (1997) for phonetic transcription of Australian English. To check transcription reliability, a second transcriber separately transcribed one 
hour of recording at Stage I and one hour at Stage 2, made up of a random selection from each session. The second transcriber was a native AustralianEnglish speaker who has a Masters degree in speech science and is trained in phonetic transcription of Australian English. Reliability analyses showed $95.63 \%$ agreement between transcribers at Stage I and $96 \cdot 88 \%$ at Stage 2 . The majority of disagreements were about vowel quality, in particular between the schwa and full vowels (making up $45^{\circ} 93 \%$ of total disagreements at Stage I and $49 \cdot 24 \%$ at Stage 2 ). The two transcribers held consensus discussions to make decisions about how to transcribe disagreements. Where consensus could not be reached, a third transcriber (the second author) was consulted to make a decision.

\section{Analysis}

The search tool in Phon was used to perform frequency counts of fricatives by word position. Consonant deletion was quantified by searching for differences in the standard and actual IPA transcriptions. The transcripts were then searched manually to determine whether the differences between fricatives in the IPA Actual and IPA Target tiers were due to speech errors or the mother using a different lexical form (e.g., the child-directed speech form horsie for horse would show up as a difference in the Target and Actual word-medial and word-final [s]), or whether it was an apparent systematic process in the sample. The exclamation hey was excluded from the $/ \mathrm{h} /$ deletion analyses. To test whether the frequency of specific speech processes increased over time, the processes word-initial $/ \mathrm{h} /$ deletion and word-final /v/ deletion were analyzed further in SPSS using binary logistic regression. To explore local effects on the processes we analyzed the number and types of lexical items in which deletion occurred, in both function and content words, using frequency counts at each child age.

Speech rate was measured to investigate whether changes in rates of deletion over time were related to changes in speech rate. Speech rate in words per second was analyzed for the entire sample at each time-point, following the procedure outlined and validated by Ko (2012). A more detailed analysis of speech rate was also performed on a subset of the data by calculating syllables per second in a random selection of sixty utterances from each mother at each child age: thirty in which deletion occurred and thirty in which it did not.

\section{RESULTS}

\section{Analysis $I$ : incidence of word-initial / $/$ / and word-final /v/ deletion in maternal speech over time}

Word-initial / $/ \mathrm{h} /$ deletion. It was hypothesized that the proportion of word-initial $/ \mathrm{h} /$ deletion in maternal speech would increase at each time point. 
BUCHAN AND JONES

TABLE 3. Raw frequencies of word-initial /h/ deletion out of possible contexts by each speaker at each average child age

\begin{tabular}{|c|c|c|c|c|}
\hline & \multicolumn{4}{|c|}{ Proportion of deletion ( $N$ deleted/ $N$ contexts) } \\
\hline & I; 6 & $2 ; 0$ & $2 ; 6$ & Total $\%$ deletion \\
\hline Erin & г8/169 & $24 /$ I I 2 & $20 / 162$ & $14 \cdot 00$ \\
\hline Cathy & $56 / 306$ & $83 / 327$ & $42 / 340$ & $18 \cdot 60$ \\
\hline Kim & $86 / 2$ I I & $87 / 252$ & $9 \mathrm{I} / 2 \mathrm{IO}$ & $39 \cdot 23$ \\
\hline Kellie & I02/377 & $201 / 434$ & $105 / 336$ & $35 \cdot 57$ \\
\hline Total $N$ & $262 / 1063$ & $395 /$ I I 25 & $258 / 1048$ & $915 / 3236$ \\
\hline Total \% deletion & $24 \cdot 65$ & $35 \cdot$ II & $24 \cdot 62$ & $28 \cdot 28$ \\
\hline
\end{tabular}

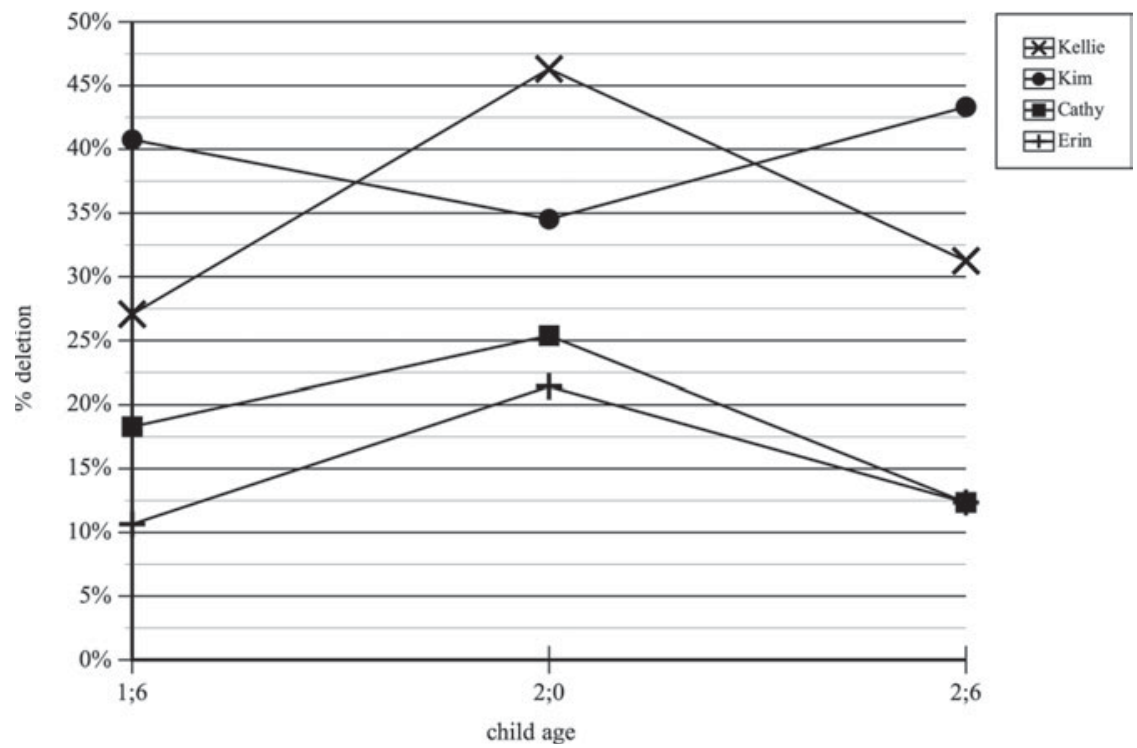

Fig. 2. Percentage word-initial $/ \mathrm{h} /$ deletion out of word-initial $/ \mathrm{h} /$ contexts by child age and speaker.

Table 3 shows the frequencies of word-initial $/ \mathrm{h} /$ deletion out of possible contexts at each average child age, and percentages of deletion for each speaker are in Figure 2. Descriptively, there was a proportional increase in deletion between child ages I; $6(24.65 \%)$ and $2 ; 0(35.1 \mathrm{I} \%)$, and a proportional decrease between 2 ; 0 and $2 ; 6(24 \cdot 62 \%)$.

To test the hypothesis that word-initial /h/ deletion is influenced by child age we performed a binary logistic regression. The outcome variable was word-initial /h/ deletion and the predictor variables were child age 


\begin{tabular}{|c|c|c|c|c|c|c|c|c|}
\hline & \multirow[b]{2}{*}{ B } & \multirow[b]{2}{*}{ s.e. } & \multirow[b]{2}{*}{ Wald } & \multirow[b]{2}{*}{$\mathrm{df}$} & \multirow[b]{2}{*}{$\mathrm{p}$} & \multirow[b]{2}{*}{$\operatorname{Exp}(B)$} & \multicolumn{2}{|c|}{$95 \%$ C. I. for $\operatorname{Exp}(B)$} \\
\hline & & & & & & & Lower & Upper \\
\hline \multicolumn{9}{|l|}{ Child age } \\
\hline I; 6 & -0.40 & O. I I & I $3 \cdot$ I 5 & I & $<0.001$ & 0.67 & 0.54 & 0.83 \\
\hline $2 ; 6$ & 0.35 & O. I I & $9.9 \mathrm{I}$ & I & 0.002 & $I \cdot 42$ & $\mathrm{I} \cdot \mathrm{I} 4$ & I 76 \\
\hline \multicolumn{9}{|l|}{ Speaker } \\
\hline Erin & $-\mathrm{I} \cdot 34$ & 0.15 & $8 I \cdot 36$ & I & $<0.001$ & 0.26 & 0.20 & 0.35 \\
\hline Cathy & $-\mathrm{I} \cdot 07$ & 0.10 & I I I 45 & I & $<0.001$ & 0.34 & 0.28 & 0.42 \\
\hline Kim & 0.02 & 0.09 & 0.05 & I & 0.82 & $\mathrm{I} \cdot 02$ & 0.85 & $I \cdot 23$ \\
\hline \multicolumn{9}{|c|}{ Child age $\times$ speaker } \\
\hline I. $6 \times$ Erin & -0.02 & $0 \cdot 36$ & 0.00 & I & 0.96 & 0.98 & 0.48 & I.99 \\
\hline $2 \cdot 6 \times$ Erin & 0.15 & 0.35 & 0.17 & I & 0.68 & $I \cdot I 6$ & 0.58 & $2 \cdot 32$ \\
\hline I. $6 \times$ Cathy & 0.63 & 0.23 & $7 \cdot 30$ & I & 0.01 & $\mathrm{I} \cdot 88$ & I. I9 & $2 \cdot 97$ \\
\hline $2 \cdot 6 \times$ Cathy & -0.03 & 0.25 & 0.01 & I & $0.9 \mathrm{I}$ & 0.97 & 0.60 & $\mathrm{I} \cdot 58$ \\
\hline $\mathrm{I} \cdot 6 \times \mathrm{Kim}$ & $I \cdot 22$ & 0.23 & $29 \cdot 08$ & I & $<0.001$ & $3 \cdot 39$ & $2 \cdot 18$ & $5 \cdot 29$ \\
\hline $2 \cdot 6 \times \operatorname{Kim}$ & $-\mathrm{I} \cdot \mathrm{I} 5$ & 0.23 & $25 \cdot 59$ & I & $<0.001$ & 0.32 & 0.20 & 0.50 \\
\hline
\end{tabular}

NOTE: The reference group for Child age is 2;0 (repeated contrast) and for Speaker is Kellie.

and speaker. Child age $(\mathrm{I} ; 6,2 ; 0$, and $2 ; 6)$ was entered as a repeated contrast making age 2 ; 0 the reference group. Table 4 shows the results of logistic regression analysis. The model has good fit to the data $\left(\chi^{2}\right.$ (I I $)=295 \cdot 36$, $p<\cdot \circ \circ \mathrm{I})$, and accounts for some of the variance (Nagelkerke $\mathrm{R}^{2}=0 \cdot \mathrm{I} 0$ ). Results indicate a significant effect of child age (Wald $\chi^{2}(2)=\mathrm{I} 6 \cdot 08$, $p<\cdot \circ \circ \mathrm{I}$ ). The odds of $/ \mathrm{h} /$ deletion are lower at child age $\mathrm{I} ; 6$ than 2 ; o (odds ratio 0.67 ), and higher at 2; 0 than $2 ; 6$ (odds ratio $1 \cdot 42$ ). The hypothesis that deletion would increase as the child got older was supported between child ages I; 6 and 2;0, while the decrease in deletion between ages 2;0 and $2 ; 6$ was unexpected.

There is also a significant effect of speaker on $/ \mathrm{h} /$ deletion (Wald $\left.\chi^{2}(3)=\mathrm{I} 9 \mathrm{I} \cdot 2 \mathrm{I}, p<\cdot 00 \mathrm{I}\right)$. The speaker Kellie was the reference group (total deletion $35.57 \%$ ), and results show that the odds of deletion were lower for Erin (odds ratio 0.26 ) and Cathy (odds ratio 0.34 ). There was no significant difference in the odds of deletion for Kim (odds ratio I·02) compared with Kellie.

Interactions between child age and speaker were tested in the logistic regression model to test whether the main effect of age was found across all speakers. Results show a significant interaction effect (Wald $\chi^{2}(6)=46 \cdot 80$, $p<\cdot \circ$ I). As shown in Table 4 , there were three significant interactions: Cathy by age $\mathrm{I} ; 6$, Kim by age $\mathrm{I} ; 6$, and Kim by age $2 ; 6$. Figure 2 shows that Kim displays a v-pattern of deletion over time, a decrease in deletion from $\mathrm{I} ; 6$ to 2 ; 0 followed by an increase from 2 ; 0 to $2 ; 6$, while Kellie, Cathy, and Erin display an inverted-v pattern, that is an increase from $\mathrm{I} ; 6$ 
TABLE 5. Raw frequencies of word-final /v/ deletion out of possible contexts by each speaker at each average child age

\begin{tabular}{lcccc}
\hline & \multicolumn{4}{c}{ Proportion of deletion $(N$ deleted/N contexts) } \\
\cline { 2 - 5 } & $\mathrm{I} ; 6$ & $2 ; 0$ & $2 ; 6$ & Total \% deletion \\
\hline Erin & $5 / 70$ & $7 / 50$ & $8 / 74$ & $\mathrm{I0} 3 \mathrm{I}$ \\
Cathy & $22 / 96$ & $32 / \mathrm{I} 32$ & $33 / \mathrm{I} 78$ & $2 \mathrm{I} \cdot 43$ \\
Kim & $\mathrm{I} 3 / 49$ & $9 / 42$ & $\mathrm{I} 9 / 82$ & $23 \cdot 70$ \\
Kellie & $7 / 76$ & $24 / \mathrm{IO} 4$ & $\mathrm{I} 5 / \mathrm{I} \mathrm{I} 4$ & $\mathrm{I} 5 \cdot 65$ \\
Total $N$ & $47 / 29 \mathrm{I}$ & $72 / 328$ & $75 / 448$ & $\mathrm{I} 94 / \mathrm{I} 067$ \\
Total \% deletion & $\mathrm{I} 6 \cdot \mathrm{I} 5$ & $2 \mathrm{I} \cdot 95$ & $\mathrm{I} 6 \cdot 74$ & $\mathrm{I} 8 \cdot \mathrm{I} 8$ \\
\hline
\end{tabular}

to 2 ; o followed by a decrease from 2 ; 0 to $2 ; 6$. Between child ages $1 ; 6$ and $2 ; 0 / \mathrm{h} /$ deletion was significantly more likely to increase for the reference group Kellie than for Kim (odds ratio 3.39). Between child ages 2; 0 and $2 ; 6$, the odds of $/ \mathrm{h} /$ deletion were significantly more likely to decrease for Kellie than Kim (odds ratio 0.32). The interaction of Cathy by child age $1 ; 6$ shows that the increase in the odds of $/ \mathrm{h} /$ deletion between ages $\mathrm{I} ; 6$ and $2 ; 0$ was significantly higher for Kellie than Cathy (odds ratio $\mathrm{I} \cdot 88$ ).

Word-final /v/ deletion. It was hypothesized that the speech process word-final / v/ deletion would proportionately increase in mothers' speech at each time-point. Table 5 shows the frequencies of word-final /v/ deletion out of possible contexts at each average child age. The percentage of word-final / v/ deletion for each speaker is shown in Figure 3. This process was not as frequent as word-initial $/ \mathrm{h} /$ deletion, so there were fewer possible contexts and fewer tokens in which the process occurred. ${ }^{1}$ Overall there was a slight increase in word-final /v/ deletion between child ages I; 6 and $2 ; 0$, from $I 6 \cdot I 5 \%$ to $2 \mathrm{I} \cdot 95 \%$, and a decrease between ages 2 ; 0 and $2 ; 6$ to I $6 \cdot 74 \%$. This inverted-v pattern resembles that for word-initial $/ \mathrm{h} /$ deletion and was partially consistent with the hypothesis: word-final /v/ deletion changed in mothers' speech over time but not in the expected direction as children aged from 2 ; 0 to $2 ; 6$.

To test the hypothesis that word-final /v/ deletion is influenced by child age we performed another binary logistic regression. Table 6 shows the results of the analysis using child age and speaker as predictors of word-final / $/ \mathrm{d}$ deletion. The model fit to the data approached significance $\left(\chi^{2}\right.$ ( I $)=$ I 8.66, $\quad p=.067 ; \quad$ Nagelkerke $\left.\mathrm{R}^{2}=0.02\right)$. Results indicate no significant effect of child age (Wald $\left.\chi^{2}(2)=2 \cdot 18, p=\cdot 33^{6}\right)$. The hypothesis

[I] Searches were performed in Phon for word-final [v] contexts that precede a word-initial labio-dental fricative $[\mathrm{v}, \mathrm{f}]$ in the following word. This environment is extremely rare in the corpus, with one case at child age I ; 6 (Cathy), none at 2;0, and four at 2;6 (I Cathy, $3 \mathrm{Kim})$. 


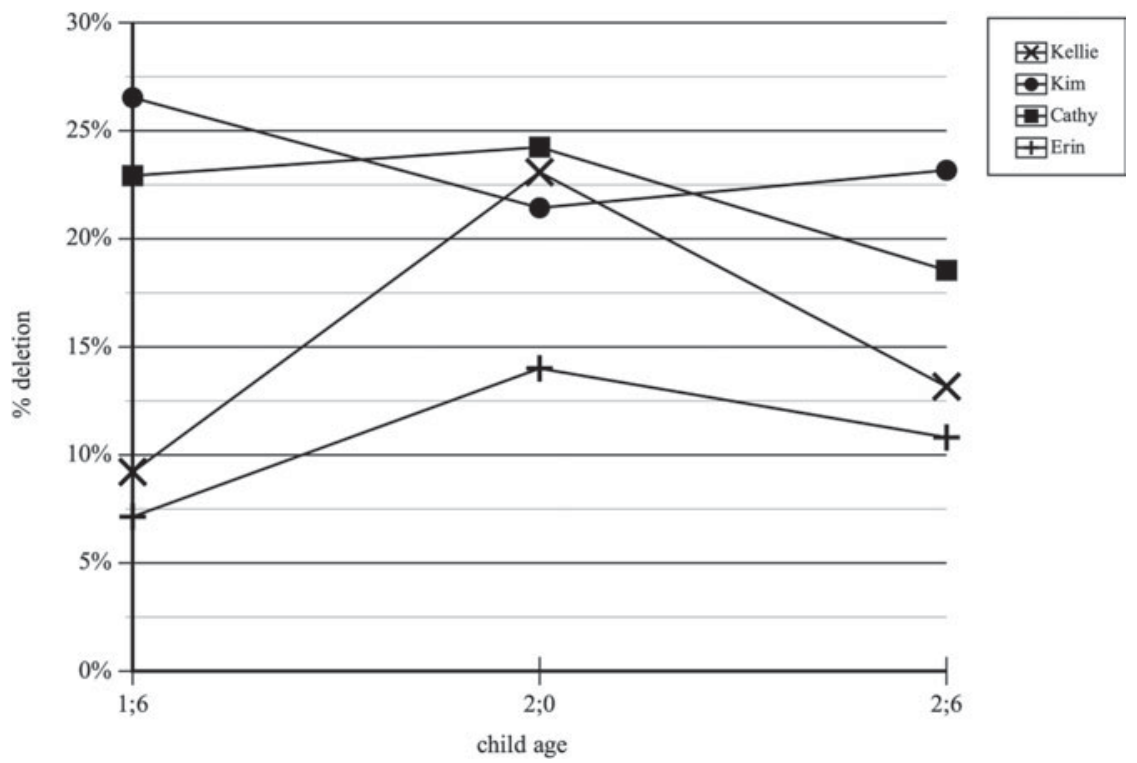

Fig. 3. Percentage word-final $/ \mathrm{v} /$ deletion out of word-final $/ \mathrm{v} /$ contexts by child age and speaker.

that word-final /v/ deletion would increase as children got older was not supported. In this model the effect of speaker approached significance (Wald $\left.\chi^{2}(3)=7 \cdot 75, p=\cdot 052\right)$. The speaker with the highest total $/ \mathrm{v} /$ deletion was the reference group (Kim, total /v/ deletion $23.70 \%$ ) and results show that the odds of deletion were marginally lower for Erin (odds ratio 0.64 ).

There was no significant interaction effect (Wald $\chi^{2}(6)=7 \cdot 48, p=\cdot 279$ ). Figure 3 suggests, however, that the pattern of $/ v /$ deletion over time depends on speaker. Kellie, Cathy, and Erin display an inverted-v pattern as they are less likely to delete at child age $2 ; 0$ than at $1 ; 6$ or $2 ; 6$, while Kim displays the opposite pattern as she is more likely to delete at $2 ; 0$ than I; 6 or $2 ; 6$. The inter-speaker patterns for word-final $/ \mathrm{v} /$ deletion over time resemble those found for word-initial $/ \mathrm{h} /$ deletion and show that within speakers there was consistency across both processes.

Analysis I discussion. It was predicted that the likelihood of deletion in mothers' speech would increase over time to reflect a gradual change from child-directed speech to inter-adult speech. The hypothesis was partially supported: word-initial $/ \mathrm{h} /$ and word-final $/ \mathrm{v} /$ deletion were more likely to occur in mothers' speech when children were 2 ; 0 than $\mathrm{I} ; 6$, but were unexpectedly less likely at $2 ; 6$ than 2 ; 0 . The change over time was significant for $/ \mathrm{h} /$ deletion but not for /v/ deletion, likely because word-final /v/ contexts were rarer in the corpus. Results also show inter-speaker 


\begin{tabular}{|c|c|c|c|c|c|c|c|c|}
\hline & \multirow[b]{2}{*}{ B } & \multirow[b]{2}{*}{ s.e. } & \multirow[b]{2}{*}{ Wald } & \multirow[b]{2}{*}{$\mathrm{df}$} & \multirow[b]{2}{*}{$\mathrm{p}$} & \multirow[b]{2}{*}{$\operatorname{Exp}(B)$} & \multicolumn{2}{|c|}{$95 \%$ C. I. for $\operatorname{Exp}(B)$} \\
\hline & & & & & & & Lower & Upper \\
\hline \multicolumn{9}{|l|}{ Child age } \\
\hline I $; 6$ & -0.34 & 0.23 & $2 \cdot 08$ & I & 0.15 & $0.7 \mathrm{I}$ & 0.45 & $I \cdot 13$ \\
\hline $2 ; 6$ & 0.09 & 0.21 & 0.17 & I & 0.68 & I.09 & 0.73 & $I \cdot 63$ \\
\hline \multicolumn{9}{|l|}{ Speaker } \\
\hline Erin & -0.44 & 0.30 & $2 \cdot 24$ & I & 0.14 & 0.64 & 0.36 & $I \cdot I 5$ \\
\hline Kellie & 0.27 & 0.25 & $\mathrm{I} \cdot \mathrm{I} 8$ & I & 0.28 & $\mathrm{I} \cdot 3 \mathrm{I}$ & $0.8 \mathrm{I}$ & $2 \cdot 14$ \\
\hline Cathy & 0.23 & 0.21 & $\mathrm{I} \cdot 22$ & I & 0.27 & $\mathrm{I} \cdot 26$ & 0.83 & $\mathrm{I} \cdot 9 \mathrm{I}$ \\
\hline \multicolumn{9}{|c|}{ Child age $\times$ Speaker } \\
\hline I $\cdot 6 \times$ Erin & 0.40 & 0.76 & 0.28 & I & 0.60 & $\mathrm{I} \cdot 50$ & 0.34 & $6 \cdot 5^{8}$ \\
\hline $2 \cdot 6 \times$ Erin & -0.06 & 0.65 & 0.01 & I & 0.93 & 0.94 & 0.26 & $3 \cdot 36$ \\
\hline I. $6 \times$ Kellie & $\mathrm{I} \cdot 57$ & 0.65 & $5 \cdot 90$ & I & 0.02 & $4 \cdot 8 \mathrm{I}$ & I.36 & I $7 \cdot 14$ \\
\hline $2 \cdot 6 \times$ Kellie & $-0.7 \mathrm{I}$ & 0.56 & $\mathrm{I} \cdot 59$ & I & 0.21 & 0.49 & 0.17 & I $\cdot 48$ \\
\hline I. $6 \times$ Cathy & I.O4 & 0.54 & $3 \cdot 68$ & I & 0.06 & $2 \cdot 8 \mathrm{I}$ & 0.98 & $8 \cdot 12$ \\
\hline $2 \cdot 6 \times$ Cathy & -0.09 & 0.44 & 0.04 & I & 0.84 & $0.9 \mathrm{I}$ & $0 \cdot 38$ & $2 \cdot 18$ \\
\hline
\end{tabular}

NOTE: The reference group for Child age is 2;0 (repeated contrast) and for Speaker is Kim.

differences, which is consistent with Ko's (2012) finding of individual variation in developmental paths of speech rate in child-directed speech. In this study the presence of siblings may have contributed to inter-speaker variation, as the mother who did not have the inverted-v pattern of deletion also had two older children who were present in many of the sessions, while with the other three mothers the target child was generally the only child in the recordings. The inverted-v effect was also stronger in one of the speakers, Kellie, than in the other two speakers who displayed the pattern. Future research on more speakers would be beneficial to examine possible causes of inter-speaker variation: a possible contributing factor is the gender of the child, as Erin and Cathy, who were mothers of girls, displayed similar patterns of a relatively shallow inverted-v while Kim and Kellie were mothers of boys and displayed greater variation. Possible effects of the children's gender is discussed further in Analysis 2.

The finding of an inverted-v pattern in three of the four speakers is surprising in the light of previous studies that have found that consonant deletion in clusters is more likely in mothers' speech to children aged 3 ; I I than 2; I I (Smith et al., 2009), and that non-standard variants become more frequent as children age from 2; 0 to 4; 0 (Foulkes et al., 2005). This could be due to the different indexical natures of the speech variables investigated in these studies, i.e., cluster reduction in the Smith et al. (2009) study, [t] variants in Foulkes et al. (2005), and /h/ and /v/ deletion in the current study. A possible interpretation of our findings in Analysis $\mathrm{I}$ is that $/ \mathrm{h} / \mathrm{and}$ /v/ deletion are non-citation speech processes in Katherine English, and 
mothers increase their use of these processes between child ages $1 ; 6$ and 2 ; 0 and decrease them as children age from 2 ; 0 to $2 ; 6$, perhaps in relation to the children's speech production. To explore this interpretation further analyses are needed to arrive at a more detailed, lexically specific understanding of the deletion processes.

Another possible explanation for the findings in Analysis I is that there is a change over time in the distribution of lexical items in which deletion occurred, and/or in the distribution of function words, which are more susceptible to reduction processes (Cutler, I993) than content words. It raises the question: Are mothers changing their pronunciation in a specific set of words? If so, then is the frequency of these words changing over time, resulting in an apparent effect of change in deletion as children get older? Thus we conducted a more fine-grained second analysis to investigate the question of how widespread /h/ and /v/ deletion are across lexical items and word class. In Analysis 2 we calculated frequencies and percentages of word-initial /h/ and word-final / $/ \mathrm{d}$ / deletion in all the lexical items in which it occurred in the corpus.

\section{Analysis 2: exploration of local effects on speech processes}

Table 7 shows the proportion of word-initial /h/ and word-final/v/ deletion across ages for each word that displayed the process. Words are listed in order of highest to lowest frequency of deletion (see 'Total $n$ deleted/ contexts' column in Table 7 ). Word-initial $/ \mathrm{h} /$ deletion occurred across a range of words at all time-points, while word-final /v/ deletion only occurred in of, have, and give. The $/ \mathrm{h} /$ items are separated by word class to examine the distributions of deletion in function and content words. At all child ages deletion was more frequent in function than content words $(30.18 \%$ and $5.91 \%$ total deletion respectively). The inverted-v pattern of deletion over time is apparent in the function words for $/ \mathrm{h} /$ deletion. In content words $/ \mathrm{h} /$ deletion decreased slightly between time-points, and /v/ deletion only occurred in three lexical items. Note that in both $/ \mathrm{h} /$ deletion in content words and / $/$ / deletion, the $\mathrm{N}$ for deleted consonants in most lexical items is very low. In particular, $/ \mathrm{h} /$ deletion was frequent in pronouns, the adverb here, and the verb have (as a main verb and an auxiliary verb). The words displaying the highest frequencies of deletion are relatively frequent overall at each time-point, indicating that changes in rates of deletion are not due to the mothers introducing or removing words from their speech as children get older.

Within Table 7 it is clear that there are approximately seven words that are high frequency and involve considerable word-initial /h/ deletion and that the inverted-v pattern of deletion over time is mostly driven by function words rather than content words. The seven words are the same 
TABLE 7. Lexical items containing word-initial/h/ and word-final /v/ deletion at each time-point

\begin{tabular}{|c|c|c|c|c|c|c|c|c|}
\hline & \multicolumn{2}{|l|}{ I $; 6$} & \multicolumn{2}{|l|}{$2 ; 0$} & \multicolumn{2}{|l|}{$2 ; 6$} & \multicolumn{2}{|c|}{ TOTAL } \\
\hline & $n$ deleted/contexts & $\%$ deletion & $n$ deleted/contexts & $\%$ deletion & $n$ deleted/contexts & $\%$ deletion & $n$ deleted/ contexts & $\%$ deletion \\
\hline \multicolumn{9}{|c|}{$/ h /$ deletion : function words } \\
\hline he & $52 / 178$ & $29 \cdot 21$ & $73 /$ I 44 & $50 \cdot 69$ & $55 /$ I I 3 & $48 \cdot 67$ & I $80 / 435$ & $4 I \cdot 38$ \\
\hline him & $84 /$ I O I & $83 \cdot 17$ & $55 / 65$ & $84 \cdot 62$ & $4 I / 5 I$ & $80 \cdot 39$ & I $80 / 2$ I 7 & $82 \cdot 95$ \\
\hline have & $25 / 145$ & I $7 \cdot 24$ & $37 / 158$ & $23 \cdot 42$ & $53 / 208$ & $25 \cdot 48$ & I I $5 / 5$ I I & $22 \cdot 50$ \\
\hline he's & $23 / I 2 I$ & I $9 \cdot 0 \mathrm{I}$ & $67 /$ I 54 & $43 \cdot 5 \mathrm{I}$ & $22 / 78$ & $28 \cdot 2 \mathrm{I}$ & I $12 / 353$ & $3 I \cdot 73$ \\
\hline here & $21 / 260$ & $8 \cdot 08$ & $52 / 259$ & 20.08 & $30 / 250$ & I $2 \cdot 00$ & г $03 / 769$ & I 3.39 \\
\hline his & $28 / 44$ & $63 \cdot 64$ & $39 / 52$ & $75 \cdot 00$ & $35 / 7 \mathrm{I}$ & $49 \cdot 30$ & $102 / 167$ & $6 \mathrm{I} \cdot 08$ \\
\hline her & I $5 / 35$ & $42 \cdot 86$ & $49 / 92$ & $53 \cdot 26$ & $8 / 36$ & $22 \cdot 22$ & $72 / 163$ & $44 \cdot 17$ \\
\hline has & $\circ / 9$ & 0.00 & $5 / 2 \mathrm{I}$ & $23 \cdot 8 I$ & $4 / 8$ & $50 \cdot 00$ & $9 / 38$ & 23.68 \\
\hline haven't & $2 /$ I I & I $8 \cdot$ I 8 & $4 / 10$ & 40.00 & $2 / 10$ & 20.00 & $8 / 3$ I & $25 \cdot 8 \mathrm{I}$ \\
\hline himself & $3 / 4$ & 75.00 & $3 / 3$ & 100.00 & $0 / 4$ & 0.00 & $6 /$ I I & $54 \cdot 55$ \\
\hline he'll & $2 / 6$ & $33 \cdot 33$ & $\mathrm{I} / 7$ & I 4.29 & $0 / \mathrm{I}$ & 0.00 & $3 / \mathrm{I} 4$ & $2 \mathrm{I} \cdot 43$ \\
\hline how & $0 / 46$ & 0.00 & $2 / 67$ & 2.99 & $\mathrm{I} / 8_{\mathrm{I}}$ & $I \cdot 23$ & $3 / 194$ & $\mathrm{I} \cdot 55$ \\
\hline had & $\mathrm{I} / \mathrm{I} 2$ & $8 \cdot 33$ & $0 / 13$ & 0.00 & $\mathrm{I} / 24$ & $4 \cdot 17$ & $2 / 49$ & 4.08 \\
\hline hasn't & $0 / 2$ & 0.00 & $2 / 4$ & $50 \cdot 00$ & $0 / \mathrm{I}$ & 0.00 & $2 / 7$ & $28 \cdot 57$ \\
\hline herself & - & - & $2 / 3$ & $66 \cdot 67$ & - & - & $2 / 3$ & $66 \cdot 67$ \\
\hline who & - & - & - & - & $\mathrm{I} / 20$ & $5 \cdot 00$ & $\mathrm{I} / 20$ & 5.00 \\
\hline $\begin{array}{l}\text { Total } \\
/ h / \text { deletion }\end{array}$ & $\begin{array}{c}256 / 974 \\
\text { : content words }\end{array}$ & \multicolumn{3}{|c|}{$/ h /$ deletion: content words } & $253 / 956$ & $26 \cdot 46$ & $900 / 2982$ & $30 \cdot 18$ \\
\hline hang & $\mathrm{I} / 30$ & 3.33 & $1 / 32$ & $3 \cdot 13$ & $1 / 33$ & 3.03 & $3 / 95$ & $3 \cdot 16$ \\
\hline head & $\mathrm{I} / \mathrm{I} 4$ & $7 \cdot 14$ & $0 / 2 \mathrm{I}$ & 0.00 & $2 / 17$ & I I 76 & $3 / 52$ & $5 \cdot 77$ \\
\hline hop & $2 / 37$ & $5 \cdot 4 \mathrm{I}$ & $\mathrm{I} / 4$ & $25 \cdot 00$ & $0 / 20$ & 0.00 & $3 / 6 \mathrm{I}$ & $4 \cdot 92$ \\
\hline Heather & $2 / 3$ & $66 \cdot 67$ & O/I I & 0.00 & $0 / 7$ & 0.00 & $2 / 2 I$ & $9 \cdot 52$ \\
\hline hit & $0 / 5$ & 0.00 & $2 / 5$ & $40 \cdot 00$ & - & - & $2 / 10$ & $20 \cdot 00$ \\
\hline hold & - & - & - & - & $2 / 15$ & I $3 \cdot 33$ & $2 / 15$ & I $3 \cdot 33$ \\
\hline $\begin{array}{l}\text { Total } \\
/ v / \text { deletion }\end{array}$ & $6 / 89$ & $6 \cdot 74$ & $4 / 73$ & $5 \cdot 48$ & $5 / 92$ & $5 \cdot 43$ & I $5 / 254$ & $\begin{array}{r}5.91 \\
5.53\end{array}$ \\
\hline of & $35 /$ I I 2 & $3 I \cdot 25$ & $39 / 124$ & $3 I \cdot 45$ & $66 / 220$ & $30 \cdot 00$ & I $40 / 456$ & $30 \cdot 70$ \\
\hline have & $8 / 145$ & $5 \cdot 52$ & $3 \mathrm{I} / \mathrm{I} 5^{8}$ & 19.62 & $7 / 208$ & $3 \cdot 37$ & $46 / 5$ I I & 9.00 \\
\hline give & $4 / 34$ & I I 76 & $2 / 46$ & $4 \cdot 35$ & $2 / 20$ & I0.00 & 8/100 & 8.00 \\
\hline Total & $47 / 29 \mathrm{I}$ & I $6 \cdot 15$ & $72 / 328$ & $2 I \cdot 95$ & $75 / 448$ & I $6 \cdot 74$ & I 94/ I 067 & I $8 \cdot$ I 8 \\
\hline
\end{tabular}




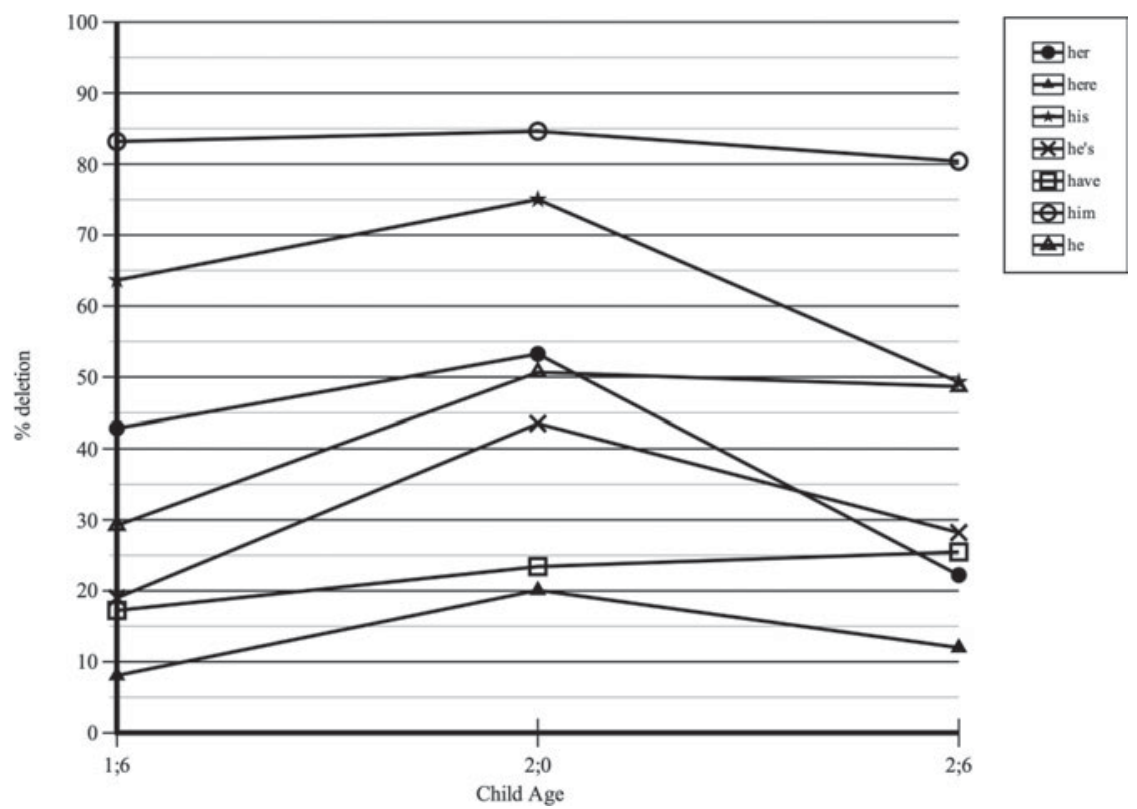

Fig. 4. Most frequent lexical items containing word-initial $/ \mathrm{h} /$ deletion at each time-point.

words at each child age and account for $94.53 \%$ of $/ \mathrm{h} /$ deletion at age $\mathrm{I} ; 6$, $94.09 \%$ at age $2 ; 0$, and $94.57 \%$ at age $2 ; 6$. It is therefore of interest to examine how $/ \mathrm{h} /$ deletion changes over time for these words. Figure 4 shows the percentage of $/ \mathrm{h} /$ deletion over time for each word. Five of the seven words display an increase in deletion between $\mathrm{I} ; 6$ and 2;0 and a decrease between $2 ; 0$ and $2 ; 6$ and are therefore contributing to the inverted-v pattern of deletion found in Analysis I. The two words that do not follow this pattern are him and have. Deletion in him is the highest of all words, between $80.00 \%$ and $83.17 \%$, and the lack of change may be due to a ceiling effect. $/ \mathrm{h} /$ deletion in have increases slightly at each time-point.

The three words containing word-final /v/ deletion are of, have, and give. Deletion in of is relatively stable over time, between $30 \cdot 00 \%$ and $31.45 \%$, while /v/ deletion in have displays the inverted-v pattern. Deletion in give displays the opposite pattern, although note that deletion in give has a very low number of occurrences at each time-point and must be interpreted with caution. The inverted-v pattern of word-final /v/ deletion therefore appears to be driven primarily by the lexical item have.

Gender differences in the use of male and female pronouns were also analyzed. Table 8 shows the number of tokens and percentage of deletion in male and female pronouns used by caregivers of boys $(N=2)$ and of girls 
TABLE 8. $/ h /$ deletion in male and female pronouns by caregivers of boys $(N=2)$ and girls $(N=2)$ at each time-point

\begin{tabular}{|c|c|c|c|c|c|c|c|c|}
\hline & \multicolumn{2}{|l|}{ I $; 6$} & \multicolumn{2}{|c|}{$2 ; 0$} & \multicolumn{2}{|l|}{$2 ; 6$} & \multicolumn{2}{|c|}{ TOTAL } \\
\hline & $\begin{array}{l}n \text { deleted/ } \\
\text { contexts }\end{array}$ & $\%$ & $\begin{array}{c}n \text { deleted/ } \\
\text { contexts }\end{array}$ & $\%$ & $\begin{array}{l}n \text { deleted/ } \\
\text { contexts }\end{array}$ & $\%$ & $\begin{array}{l}n \text { deleted/ } \\
\text { contexts }\end{array}$ & $\%$ \\
\hline \multicolumn{9}{|l|}{ Speech to boys } \\
\hline Male pronouns & I $37 / 306$ & $44 \cdot 77$ & $192 / 325$ & $59 \cdot \circ 8$ & I26/239 & $52 \cdot 72$ & $455 / 870$ & $52 \cdot 30$ \\
\hline Female pronouns & $12 / 16$ & 75.00 & $15 / 32$ & $46 \cdot 88$ & $4 / 5$ & 80.00 & $3 \mathrm{I} / 53$ & $58 \cdot 49$ \\
\hline Speech to girls & & & & & & & & \\
\hline Male pronouns & $58 /$ I 48 & $39 \cdot 19$ & $46 / 100$ & $46 \cdot 00$ & $27 / 79$ & $34 \cdot I 8$ & I $31 / 327$ & $40 \cdot 06$ \\
\hline Female pronouns & $3 / 19$ & I 5.79 & $36 / 6_{3}$ & $57 \cdot 14$ & $4 / 3 \mathrm{I}$ & 12.90 & $43 / I_{1} 3$ & 38.05 \\
\hline
\end{tabular}

$(N=2)$. Relevant male pronouns are much more frequent overall than female pronouns. Male pronouns in mothers' speech to boys had a higher rate of deletion than in speech to girls $(52 \cdot 30 \%$ and $40 \cdot 06 \%$ deletion respectively). However, for male pronouns, the inverted-v pattern of $/ \mathrm{h} /$ deletion occurred in speech to both boys and girls. Female pronouns were more frequent in speech to girls but had a higher rate of deletion in speech to boys $(58 \cdot 49 \%)$ than to girls $(38 \cdot 05 \%)$. The inverted-v pattern of $/ \mathrm{h} /$ deletion occurred in female pronouns in speech to girls, while in speech to boys the opposite pattern occurred in female pronouns (though note the small number of tokens at child ages $1 ; 6$ and $2 ; 6$ ).

Analysis 2 discussion. In Analysis I we found an inverted-v pattern of $/ \mathrm{h} /$ and /v/ deletion as children aged from $\mathrm{i} ; 6$ to $2 ; 0$ to $2 ; 6$, and Analysis 2 was performed to examine $/ \mathrm{h} /$ and $/ \mathrm{v} /$ deletion in lexically specific contexts. Results showed changes in deletion occurred across a specific set of function words. The words containing the highest frequencies of deletion were function words and were the same across each child age. These words accounted for most of the deletion (94\%) at each time-point. This finding suggests overall changes in deletion were not due to mothers introducing new words or removing other words from their speech as children aged.

Analysis 2 also indicates most deletion occurred in function words. In English conversational speech function words tend to be unstressed and contain reduced vowel forms compared with content words (Cutler, I 993), so it is unsurprising that consonants are also reduced, or in this case deleted, in function words. Function words are also high frequency in child-directed speech relative to content words (Shi, Werker \& Cutler, 2006), and the finding that phonetic variation is high in these words has implications for children's word learning that will be returned to in the 'General discussion'.

Possible gender differences were also revealed. Overall there was proportionately more $/ \mathrm{h} /$ deletion in mothers' speech to boys than to girls in 
both male and female pronouns. The inverted-v pattern of deletion over time was found in male pronouns in all speakers, but in female pronouns it occurred in speech to girls but not boys. With only four speakers these findings cannot be generalized, but they do appear to support the Tyneside English study (Foulkes et al., 2005), which found that caregiver speech to boys contained more vernacular variants of $[\mathrm{t}]$ than speech to girls, which contained more standard variants. Foulkes et al. (2005) suggested that these gender differences may be due to mothers fine-tuning their speech to children's developing gender identities, as in adult speech males tend to use more non-standard phonological variants than females. Horvath's (i 985) study on adult Australian English speakers from Sydney did find that $/ \mathrm{h} /$ deletion generally occurred more in male than female speech, so the gender identity explanation could apply to the current findings, although more data are needed to explore this further.

\section{Analysis 3: effect of speech rate}

A second possible explanation for the finding of change in deletion over time is that it is a function of speech rate, and the rate of deletion changes because mothers modify their rate of speech as children age. If this were the case we could expect to find an association between more deletion and faster speech, and that mothers' speech rate across child age follows the same pattern as deletion, i.e., an increase between ages I; 6 and 2; 0 and a decrease between 2 ; 0 and $2 ; 6$.

To investigate this we calculated speech rate in words per second in each utterance, following the method used and validated by Ko (2012). Transcripts were segmented by utterance in Phon, where utterances were units of speech with pause boundaries at each end, and speech rate was calculated from the segmentation time stamps. Following the procedure of Ko (2012), paralinguistic notations (e.g., crying, laughter) were omitted and utterances were excluded when the duration was longer than Io seconds $(N=\mathrm{I} 2)$, as these were likely to contain pauses that had not been segmented, and where they contained unintelligible speech and phonological fragments $(N=396)$. This left 5,856 utterances at age I; 6, 5,6 I 3 at $2 ; 0$, and 6,685 at $2 ; 6$.

A one-way ANOVA indicated a significant effect of child age on speech rate $\left(F\left(2\right.\right.$, I $_{1}$, I $\left._{5} \mathrm{I}\right)=6$ I $\left._{3} 35, p<\cdot \circ \circ \mathrm{I}\right)$. Games-Howell post-hoc comparisons revealed mothers' speech rate at child age $2 ; 6$ was significantly higher than I ; $6(M=0.20,95 \%$ CI [0.1 $5,0.25], p<.00 \mathrm{I})$ and $2 ; 0\left(M=0 . \mathrm{I}^{2}, 95 \% \mathrm{CI}\right.$ [0.1 $3,0.23], p<\cdot \circ \circ \mathrm{I})$. There was no significant difference between $\mathrm{I} ; 6$ and 2; $0(M=0.02,95 \%$ CI [ $-0.03,0.07], p=.557)$. Thus, mothers' speech rate did not significantly change as children aged from $\mathrm{I} ; 6$ to $2 ; 0$, and significantly increased between 2 ; 0 and $2 ; 6$. 
A more detailed analysis of speech rate in syllables per second was performed on a subset of 682 utterances in which word-initial $/ \mathrm{h} /$ and word-final / $/ \mathrm{s}$ deletion occurred. These are referred to here as deletion utterances (deletion occurred) and non-deletion utterances (containing word-initial /h/ or word-final /v/ contexts but with no deletion occurring). Overall there was little difference in mean speech rates between utterances containing deletion and no deletion $(M=3.26$ and 3.06 syllables per second respectively). An independent samples $t$-test confirmed that the difference was not significant $(t(68 \mathrm{I})=-\mathrm{I} \cdot 354, p=\cdot \mathrm{I} 76)$.

In this subset of utterances, mean speech rate increased slightly at each time-point (child age $\mathrm{I} ; 6 \mathrm{M}=\mathbf{2} \cdot 88$, child age $2 ; 0 \mathrm{M}=3 \cdot \mathrm{I} \mathrm{I}$, child age $2 ; 6 \mathrm{M}=3 \cdot 43$ ). A one-way ANOVA showed a significant difference between child age for adults' speech rate $(F(2,680)=9 \cdot 58, p<\cdot 0 \circ \mathrm{I}$, adjusted $\mathrm{R}^{2}=0.025$ ), indicating child age contributed to only $2.5 \%$ of the variance in speech rate. A REGWQ post-hoc test indicated that speech rate was significantly faster at child age $2 ; 6$ than at $\mathrm{I} ; 6(p<\cdot 00 \mathrm{I})$ and $2 ; \circ(p=\cdot 03 \mathrm{I})$. The difference between $\mathrm{I} ; 6$ and 2 ; 0 was not significant $\left(p=\cdot_{1} 5_{6}\right)$. Thus the results from the more fine-grained analysis of the subset were the same as those found in the analysis of speech rate in the whole sample: mothers' speech rate did not significantly change as children aged from $1 ; 6$ to $2 ; 0$, and got slightly faster between $2 ; 0$ and $2 ; 6$.

\section{GENERAL DISCUSSION}

The present study is the first to examine phonetic variation in maternal speech in a longitudinal corpus of Australian English. Two non-citation speech processes were analysed in mothers' speech when their children were aged $\mathrm{I} ; 6,2 ; 0$, and $2 ; 6$. Based on the few studies that have investigated phonological variation in input to children after the first year of life, it was expected that variants containing consonant deletion would become more frequent in mothers' speech as their children got older. Overall findings suggest that word-initial /h/ and word-final /v/ deletion are phonological processes in Katherine English that occur across a set of lexical items. Mothers increase deletion as children age from I; 6 to 2;0 and decrease deletion as children age from $2 ; 0$ to $2 ; 6$, and these changes do not appear to be driven by speech rate. Results also showed inter-speaker variation: the inverted-v effect over time appeared in three of the four speakers and was stronger in one of the speakers who displayed the pattern relative to the other two. The effect is therefore a preliminary finding and will need to be interpreted with caution.

The increase in the proportion of $/ \mathrm{h} /$ and $/ \mathrm{v} /$ deletion between child ages I; 6 and $2 ; 0$ is consistent with literature suggesting mothers use more non-citation speech processes and correspondingly fewer standard phonetic 
variants as children get older. There was, however, an unexpected decrease in both $/ \mathrm{h} /$ and $/ \mathrm{v} /$ deletion in mothers' speech between 2;0 and 2;6, although the results for $/ \mathrm{v} /$ deletion were not statistically significant at either interval. Previous research suggests that phonetic variation in speech input to children exposes them to socioindexical variation, and change over time is due to mothers' gradually shifting their speech style to become more like inter-adult speech (Foulkes et al., 2005). While this may explain the current finding of an increase in deletion between $\mathrm{I} ; 6$ and $2 ; 0$, the question remains of why deletion proportionately decreased in maternal speech between 2;0 and $2 ; 6$. The current findings suggest that mothers change their speech style as children get older, using more non-citation speech processes between $\mathrm{I} ; 6$ and $2 ; 0$ and then shifting back to using fewer processes at $2 ; 6$. Before interpreting these results in reference to mothers' style-shifting, however, it was important to consider whether changes in deletion over time were due to changing lexical distributions in the corpus, or were a function of speech rate.

When we examined the distribution of $/ \mathrm{h} /$ and $/ \mathrm{v} /$ deletion across lexical items we found that deletion occurred in the same set of words at each time-point, and that most of these words displayed the inverted-v pattern of deletion over time. The results provide evidence that $/ \mathrm{h} /$ and $/ \mathrm{v} /$ deletion are phonological processes occurring in a set of words, or one particular item (have) in the case of $/ \mathrm{v} /$ deletion, and are not simply due to changing distributions of words with word-initial /h/ and word-final /v/ contexts.

Interestingly, this analysis also showed that deletion was most frequent in function words rather than content words, and that the significant changes in $/ \mathrm{h} /$ deletion over child age were due to changes in function words. This is consistent with the literature on phonological differences in content and function words in English. At the prosodic level, function words are frequently unstressed, and at the segmental level they are likely to be realized with weak vowels, usually schwa (Cutler, I 993). The current study suggests that in addition to vowel reduction, function words contain high variation in consonants, relative to content words. Function words also have a high token frequency relative to content words in English, in both inter-adult and child-directed speech (see Shi et al., 2006, for calculations of type-token ratios in function and content words in corpora from CHILDES; MacWhinney, 2000).

According to exemplar-based models it is possible that children may have more robust information about high-frequency words in long-term memory, as a greater number of perceived tokens may result in a child having more distributional information about the word. It is, however, not known whether the frequency of tokens in the input is proportionately represented in the exemplar store. Phonological information in high-frequency words in 
the input may in fact be less likely to be perceived and thus represented in memory because they are more phonetically reduced more often and contain fewer phonological cues than low-frequency words (Cutler, I993; Monaghan et al., 2005). Low-frequency words might also have an advantage in novelty and saliency of new information. ${ }^{2}$ It would be interesting for future studies to examine longitudinally children's perceptions and use of phonological cues in high- and low-frequency items to investigate any relationship with the current finding of variation in the input at different child ages.

We tested another alternative explanation for change in deletion in maternal speech over time by analyzing the mean speech rate of each speaker at each time point. It is well known that speech rate is related to segmental deletion, with deletion more likely in faster speech (e.g., Koreman, 2006). It is therefore possible that the inverted-v pattern of deletion found in the current study was a result of mothers using faster speech at child age 2;0 than at $1 ; 6$ or $2 ; 6$. Speech rate may also play a subtler role as a component of style. Both high speech rate and segmental deletion are features of hypoarticulation, or non-citation speech, where reduction is the result of a trade-off between production ease for the speaker and perception ease for the listener (Lindblom, I990). If change in speech rate was accounting for the change in deletion found in the current study then we expected speech rate would display a similar inverted-v pattern over the three time-points. Instead we found that overall speech rate did not significantly differ between $\mathrm{r} ; 6$ and $2 ; 0$ and increased between $2 ; 0$ and $2 ; 6$, although the latter effect was small at less than half a syllable per second difference. Further, there was no significant difference in speech rate between utterances containing $/ \mathrm{h} /$ and $/ \mathrm{v} /$ deletion and utterances where $/ \mathrm{h} /$ and $/ \mathrm{v} /$ were fully realized. These findings indicate that changes in deletion over time were not due to changes in speech rate, as deletion and speech rate both displayed different patterns of change over the three time-points. The lack of difference in speech rate between utterances with and without $/ \mathrm{h} /$ and $/ \mathrm{v} /$ deletion provided further evidence that in this sample deletion is not, or at least not primarily, driven by speech rate changes.

It appears that the change in deletion over time found in this study was not an artefact of changing distributions of lexical items, nor could it be accounted for by mothers' speech rate. We thus return to the possibility that rates of $/ \mathrm{h} /$ and $/ \mathrm{v} /$ deletion in maternal speech change with the age of the child. There are at least two plausible explanations for this: (i) that mothers are modelling forms differentially as children age, and (ii) that deletion rates vary with types of speech acts (e.g., questions, recasts, and repetitions,

[2] We thank an anonymous reviewer for raising these issues for us. 
which could be frequent as children become more verbal) and social interactions (e.g., play, teaching, behaviour management) and the distributions of these shift with child age. Note that these are not mutually exclusive explanations and both may be components of fine-tuning-mothers (consciously or not) adjust phonetic variation over time as children develop knowledge of the phonology of their home language as well as across the different speech acts and social contexts in which variation is used. Because there is so little previous research on sociolinguistic markers in regional Australian English, it is not clear whether /h/ and / $/$ deletion contain socioindexical information beyond being non-citation speech processes, and further research on this is needed to draw any strong conclusions on the indexical information children may acquire from being exposed to this variation.

Recent studies on phonetic variation in caregiver speech examined different indexical variables to those in the current study. They found a slow linear increase in mothers' use of non-standard variants over time as their speech gradually became more like inter-adult speech (Foulkes et al., 2005; Smith et al., 2009). However, the mixed findings in older studies on clarification and reduction processes in child-directed speech did suggest that the different findings may be due to the different ages of the children in the studies (Cruttenden, I 994). Vowel clarification was found mostly in speech to children who were prelinguistic or producing single words (BernsteinRatner, I984a), while speech to older children was found to contain more consonant reduction and unintelligible segments than speech to adults (Bard \& Anderson, I983; Shockey \& Bond, I980). The non-linear change over time found in the present study is consistent with Cruttenden's ( I 994) argument that the apparent mixed findings of these early studies may be explained by the different functions of child-directed speech at different ages. The current finding of an inverted-v pattern in deletion may indicate that mothers follow clarification modifications with a period of reduction modifications as children start producing multiword utterances (by around two years of age), and then revert to clarification (by $2 ; 6$ ). Further research is needed to investigate whether the current finding of the inverted-v pattern over time is specific to the phonological processes of $/ \mathrm{h} /$ and $/ \mathrm{v} /$ deletion or whether it is also found in other phonological variables in speech to children aged $\mathrm{I} ; 6$ to $2 ; 6$.

If phonetic variability in speech to children serves different functions at different times then we might expect mothers to fine-tune differentially as their child's language develops. Mothers' use of more standard clarified forms may be particularly important when frequency distributions of exemplars are relatively newly formed in children's memories, and use of deleted or reduced forms may be more important when children are learning the alternate phonetic forms common in non-citation inter-adult speech and 
the socioindexical associations. Full standard forms may then become important again as children start producing multiword utterances and mothers become aware of their child's pronunciation. This may explain the decrease in deletion after 2 ; 0 , as this is when most of the children start producing multiword utterances and could indicate that mothers are starting to fine-tune to children's productive language.

Another possibility is that mothers' use of phonetic variation is related to types of speech acts and social interactions, and that there was less deletion in more formal contexts. Previous research has found relationships between mothers' use of sociolinguistic markers and speech style, with standard phonetic variants more frequent in formal contexts and the local vernacular variants more frequent in informal contexts (Smith et al., 2007). It would be of interest to do further research with the current corpus to investigate whether $/ \mathrm{h} /$ and $/ \mathrm{v} /$ deletion is related to speech style, interaction contexts, and sentence types, and whether the distributions of these change in mothers' speech as children get older.

The results of this study reveal a non-linear change in deletion in maternal speech over time; further research is needed to understand why mothers make differential segmental modifications as their children age. The current study is limited by the relatively small number of participants, and studies with more speakers are needed in order to understand the nature and extent of individual differences in phonological variation. These findings open several avenues for further investigation. For example, future studies could examine the phonological modifications mothers make when they are specifically modelling speech for children, such as through repetition and explicit teaching which may involve hyperarticulation, and how this changes as children progress from producing single-word to multiword utterances. Further research could also investigate the relationship between deletion and speech rate in maternal speech, as the current finding that speech rate increases as deletion decreases between 2;0 and 2;6 in mothers' speech was unexpected. In particular it would be useful to have more time-points to examine how speech rate and deletion change over time and whether deletion 'catches up' to speech rate, or vice versa, in relation to children's productions. Further time-points and more speakers are also needed in order to understand inter-speaker variation and whether there are different trajectories of phonological modifications in maternal speech over time, and again how these may relate to the child's language development. Further investigation of children's productions over time is needed to test different theoretical explanations for the pattern of adult speech found here. Experimental investigation of children's receptive knowledge of phonetic variation at different ages would also be relevant to help elucidate how their phonological representations are shaped by phonetic variation in the input. 


\section{REFERENCES}

Akhtar, N. (2005). The robustness of learning through overhearing. Developmental Science $\mathbf{8}$, I 99-209.

Au, T. K., Knightly, L. M., Jun, S. A. \& Oh, S. (2002). Overhearing a language during childhood. American Psychological Society 13, 238-43.

Bard, E. G. \& Anderson, A. (I983). The unintelligibility of speech to children. Fournal of Child Language ro, 265-92.

Bernstein-Ratner, N. (I984a). Patterns of vowel modification in mother-child speech. Fournal of Phonetics II, 557-78.

Bernstein-Ratner, N. (1984b). Phonological rule usage in mother-child speech. Fournal of Phonetics 12, 245-54.

Buchan, H. (2013). Phonetic variation in Gurindji Kriol and northern Australian English: a longitudinal study of fricatives in maternal speech. Unpublished doctoral dissertation, University of Wollongong, Australia.

Chevrot, J. P., Dugua, C. \& Fayol, M. (2009). Liaison acquisition, word segmentation and construction in French: a usage-based account. Fournal of Child Language 36, $557-96$.

Chevrot, J.P., Nardy, A. \& Barbu, S. (20II). Developmental dynamics of SES-related differences in children's production of obligatory and variable phonological alternations. Language Sciences 33, I80-9 I.

Cox, F. M. \& Palethorpe, S. (2004). The border effect: vowel differences across the NSW/ Victorian border. In C. Moskovsky (ed.), Proceedings of Australian Linguistic Society Conference, I-I4. Newcastle, Australia: Australian Linguistics Society.

Cox, F. M. \& Palethorpe, S. (2007). Illustrations of the IPA: Australian English. Fournal of the International Phonetic Association 37, 341-50.

Cox, F. M. \& Palethorpe, S. (2010). Broadness variation in Australian English speaking females. In M. Tabain, J. Fletcher, D. Grayden, J. Hajek \& A. Butcher (eds.), Proceedings of the I2th Australasian International Conference on Speech Science and Technology, I 75-78. Melbourne: Australasian Speech Science and Technology Association (ASSTA).

Cruttenden, A. (I 994). Phonetic and prosodic aspects of baby talk. In C. Gallaway \& B. J. Richardson (eds.), Input and interaction in language acquisition, $135-52$. Cambridge: Cambridge University Press.

Cutler, A. (I993). Phonological cues to open- and closed-class words in the processing of spoken sentences. Fournal of Psycholinguistic Research 22, I09-3 I.

Fernald, A., Taeschner, T., Dunn, J., Papousek, M., de Boysson-Bardies, B. \& Fukui, I. (I989). A cross-language study of prosodic modifications in mothers' and fathers' speech to preverbal infants. Fournal of Child Language 16, 477-50 I .

Foulkes, P. \& Docherty, G. (2006). The social life of phonetics and phonology. Fournal of Phonetics 34, 409-38.

Foulkes, P., Docherty, G. \& Watt, D. (2005). Phonological variation in child-directed speech. Language 81, I 77-206.

Harrington, J., Cox, F. \& Evans, Z. (I997). An acoustic phonetic study of broad, general, and cultivated Australian English vowels. Australian Fournal of Linguistics r7, I $55-84$.

Horvath, B. M. (1985). Variation in Australian English: the sociolects of Sydney. Cambridge: Cambridge University Press.

Ingram, J. C. L. (I989). Connected speech processes in Australian English. Australian Fournal of Linguistics, 9, $2 \mathrm{I}-49$.

Jones, C., Meakins, F. \& Buchan, H. (20I I). Comparing vowels in Gurindji Kriol and Katherine English: citation speech data. Australian Fournal of Linguistics 31, 305-26.

Jusczyk, P. W., Cutler, A. \& Redanz, N. J. (I993). Infants' preference for the predominant stress patterns of English words. Child Development 64, 675-87.

Jusczyk, P. W., Friederici, A. D., Wessels, J. M. I., Svenkerud, V. Y. \& Jusczyk, A. M. (I993). Infants' sensitivity to the sound patterns of native language words. Fournal of Memory and Language 32, 402-20. 
Jusczyk, P. W., Luce, P. A. \& Charles-Luce, J. (I994). Infants' sensitivity to phonotactic patterns in the native language. Fournal of Memory and Language 33, 630-45.

Kerswill, P. \& Williams, A. (2000). Creating a New Town koine: children and language change in Milton Keynes. Language in Society 29, 65-1 15.

Ko, E. S. (2012). Nonlinear development of speaking rate in child-directed speech. Lingua I22, $84 \mathrm{I}-57$.

Koreman, J. (2006). Perceived speech rate: the effects of articulation rate and speaking style in spontaneous speech. Fournal of the Acoustic Society of America II9, 582-96.

Kuhl, P. K., Andruski, J. E., Chistovich, I. A., Chistovich, L. A., Kozhevnikova, E. V., Ryskina, ... \& Lacerda, F. (I997). Cross-language analysis of phonetic units in language addressed to infants. Science 277, 684-86.

Kuhl, P. K., Williams, K. A., Lacerda, F., Stevens, K. N. \& Lindblom, B. (I992). Linguistic experience alters phonetic perception in infants by 6 months of age. Science 255, 606-08.

Labov, W. (1989). The child as a linguistic historian. Language Variation and Change $\mathbf{I}$, $85-97$.

Labov, W. (2001). Principles of linguistic change. Volume 2: Social factors. Oxford: Blackwell.

Lee, S. \& Davis, B. (2010). Segmental distribution patterns of English infant- and adult-directed speech. Fournal of Child Language 37, 767-91.

Lee, S., Davis, B. \& MacNeilage, P. F. (2008). Segmental properties of input to infants: a study of Korean. Fournal of Child Language 35, 59i-6 I 7 .

Lindblom, B. (I990). Explaining phonetic variation: a sketch of the H\&H theory. In W. J. Hardcastle \& A. Marchal (eds.), Speech production and speech modelling, 403-39. Dordrecht: Kluwer Academic Publishers.

Liu, H. M., Tsao, F. M. \& Kuhl, P. K. (2009). Age-related changes in acoustic modifications of Mandarin maternal speech to preverbal infants and five-year-old children: a longitudinal study. Fournal of Child Language 36, 909-22.

MacWhinney, B. (2000). The CHILDES project: tools for analyzing talk, $3 \mathrm{rd}$ edn. Mahwah, $\mathrm{NJ}$ : Lawrence Erlbaum Associates.

Martinez-Sussmann, C., Akhtar, N., Diesendruck, G. \& Markson, L. (201 I). Orienting to third-party conversations. Fournal of Child Language 38, 273-96.

Meakins, F. (201 I). Case marking in contact: the development and function of case morphology in Gurindji Kriol. Amsterdam: John Benjamins.

Mitchell, A. G. \& Delbridge, A. (1965). The pronunciation of English in Australia. Sydney: Angus \& Robertson.

Monaghan, P., Chater, N. \& Christiansen, M. H. (2005). The differential role of phonological and distributional cues in grammatical categorisation. Cognition 96, I43-82.

Munson, B., Edwards, J. \& Beckman, M. E. (20II). Phonological representations in language acquisition: climbing the ladder of abstraction. In A. C. Cohn, C. Fougeron \& M. K. Huffman (eds.), Handbook of laboratory phonology. Oxford: Oxford University Press.

Pierrehumbert, J. B. (2003). Phonetic diversity, statistical learning, and acquisition of phonology. Language and Speech 46, I I 5-54.

Roberts, J. (I 997). Acquisition of variable rules: a study of (-t,d) deletion in preschool children. Fournal of Child Language 24, 35 I-72.

Rose, Y., Hedlund, G. J., Byrne, R., Wareham, T. \& MacWhinney, B. (2007). Phon I·2: a computational basis for phonological database elaboration and model testing. In P. Buttery, A. Villavicencio \& A. Korhonen (eds.), Proceedings of the Workshop on Cognitive Aspects of Computational Language Acquisition, I7-24. Stroudsburg, PA: ACL. For recent developments see $<$ http://phon.ling.mun.ca/phontrac/wiki/ $>$.

Shi, R., Werker, J. F. \& Cutler, A. (2006). Recognition and representation of function words in English-learning infants. Infancy ro, I 87-98.

Shockey, L. \& Bond, Z. S. (I980). Phonological processes in speech addressed to children. Phonetica 37, 267-74. 
Smith, J., Durham, M. \& Fortune, L. (2007). 'Mam, my trousers is fa'in doon!': community, caregiver and child acquisition of variation in a Scottish dialect. Language Variation and Change 19, 63-99.

Smith, J., Durham, M. \& Fortune, L. (2009). Universal and dialect-specific pathways of acquisition: caregivers, children and $\mathrm{t} / \mathrm{d}$ deletion. Language Variation and Change 2r, $69-95$.

Snow, C. E. (I 977). Mothers' speech research: from input to interaction. In C. E. Snow \& C. Ferguson (eds.), Talking to children: language input and acquisition, $3 \mathrm{I}-5 \mathrm{I}$. Cambridge: Cambridge University Press.

Soderstrom, M. (2007). Beyond babytalk: re-evaluating the nature and content of speech input to preverbal infants. Developmental Review 27, 50 I-32.

Stern, D. N., Spieker, S. \& Barnett, R. K. (1983). The prosody of maternal speech: infant age and context related changes. Fournal of Child Language Io, I-I 5 .

Tagliamonte, S. A. \& Temple, R. (2005). New perspectives on an ol' variable: $(t, d)$ in British English. Language Variation and Change 17, 28I-302.

Tollfree, L. F. (I999). South-east London English: discrete versus continuous modelling of consonantal reduction. In P. Foulkes \& G. J. Docherty (eds.), Urban Voices, I6 $6_{3}-84$. London: Arnold.

Tollfree, L. F. (200I). Variation and change in Australian English consonants. In D. Blair $\&$ P. Collins (eds.), Varieties of English around the world: English in Australia, 45-67. Amsterdam: Benjamins.

Wells, J. C. (1982). Accents of English. Cambridge: Cambridge University Press.

Williams, A. \& Kerswill, P. (I999). Dialect levelling: continuity vs. change in Milton Keynes, Reading and Hull. In P. Foulkes \& G. J. Docherty (eds.), Urban Voices, I41-62. London: Arnold.

Youssef, V. (I99I). Variation as a feature of language acquisition in the Trinidad context. Language in Society 22, 257-74. 